\title{
THE DYNAMICS OF INDONESIAN INFLATION: WHAT CAN WE LEARN FROM INFLATION DISAGGREGATION?
}

\author{
IGP Wira Kusuma ${ }^{1}$
}

\begin{abstract}
This paper employs disaggregated data of inflation combined with Factor Augmented Vector Auto Regression (FAVAR) to explore the price behaviour in Indonesia. The main finding of this analysis is that price behaviour in Indonesia exhibits heterogeneity. It is evident not only in terms of the magnitude, but also in the direction and the speed of adjustment to the new equilibrium in response to interest rate shock. Price volatility is mainly related to sector specific shocks instead of macroeconomic shocks. Another finding is, the price puzzle weakens once ITF is adopted.
\end{abstract}

Keywords: price disaggregation, inflation, FAVAR, price puzzle.

JEL classification: C32, E31, E52

1 IGP Wira Kusuma PhD is an economist of Bank Indonesia. Email: kusuma@bi.go.id. The opinions expressed herein are those of the author and do not necessarily represent those of Bank Indonesia. 


\section{INTRODUCTION}

The fundamental question about the extent of price stickiness is one of the central debates in the extensive macroeconomic literature, in which it is agreed that monetary policy changes have transitory effects on the volume of goods and services because of price stickiness. The magnitude and the persistence of the effects vary and depend on the degree of price stickiness. The literature in general uses aggregate data for prices. It finds that aggregate prices do not respond to an unanticipated monetary policy shock immediately, but with some lags.

The conclusions derived from analysis using aggregated and disaggregated prices may be different. For instance, Christiano, Eichenbaum and Evans (1999) recorded, that with various identification in their VAR model, the aggregate price does not respond substantially after an un-anticipated monetary policy shock or monetary contraction, and then starts declining for approximately 18 months. As more detailed price data becomes available, the research that explores these micro data has been growing substantially.

Some support the previous findings; others find contrary results. Bils and Klenow (2004), who examine 350 categories of goods and services, find that prices in the US are much more volatile. Bunn and Ellis (2012), who examine price behavior in the UK using micro data, conclude that the frequency of price changes is not fixed over time. Golosov and Lucas (2007) also use micro data from Bils and Klenow (2004) to calibrate their menu cost model. They again find that prices are more flexible. Using disaggregated data on price indices, Boivin, Giannoni and Mihov (2009) are able to explain why the impulse responses of aggregated and disaggregated prices are different. They conclude that one should distinguish the source of the shocks. The rigidity found at the aggregated level is influenced by macroeconomic shocks, while the flexibility found in the disaggregated level is related to sector specific shocks.

These different explanations imply that it is desirable to use a more detailed data set. A richer and a more thorough analysis should be conducted to provide more accurate policy recommendations. This paper use disaggregated level data to answer the following 3 (three) fundamental questions, first, what is the extent of price flexibility in Indonesia? second, what is the response of inflation at an aggregated and disaggregated level to monetary policy shocks?; and third, what policy implications can be derived from this analysis?

Given the above research questions, the contribution of this paper should be of greatest value for policy makers, as the empirical findings could help to guide them when setting their monetary policy. Moreover, this is the first analysis to use disaggregated Indonesian price data using FAVAR. In terms of the methodology, some modifications and combinations of data also contribute new insights to the literature.

The following section explains the theory and literature studies. Section three discuss the methodology and the data. The empirical findings are presented in section four, while section five provides conclusion and policy implications. 


\section{THEORY}

The fundamental question about the extent of price stickiness is one of the central debates in the extensive macroeconomic literature, in which it is agreed that monetary policy changes have transitory effects on the volume of goods and services because of price stickiness. The magnitude and the persistence of the effects vary and depend on the degree of price stickiness. The literature in general uses aggregate data for prices. It finds that aggregate prices do not respond substantially to an unanticipated monetary policy shock immediately, but with some lags. As more detailed price data becomes available, the research that explores these micro data has been growing substantially. Some support the previous findings; others find contrary results. In this section, we review some of the relevant literature.

We start with Bils and Klenow (2004), henceforth BK, who examine price behaviour in the US. They focus on whether prices are more flexible or rigid. The paper uses unpublished data from the Bureau of Labor Statistics (BLS) covering the period 1995-1997 and divides them into 350 categories of goods and services. The data represent around 70 percent of consumer expenditure. To measure the price changes, they use a simple average of the monthly frequencies of price changes in 1995, 1996 and 1997 of each item. Their research finds that the prices of both durable and nondurable goods change more than the prices of services. Among the seven subgroups of $\mathrm{CPI}$, the most flexible one is transportation. On the other hand, the most inflexible is the price of medical and entertainment subgroups. At the same time, they observe the inflation volatility and persistence of 123 goods by employing an AR (1) process. BK find that many more goods and services witness prices changes and move frequently than in previous studies.

Bils and Klenow (2004) treat sales prices as price changes. As a result, across the whole consumer price index they find the median duration of price changes is around four months. On the other hand, Nakamura and Steinson (2008) find that the median duration is around nine months if sales are excluded. This difference raises the question on how great the effect of monetary policy should be on real variables, since this effect depends on price stickiness. Meanwhile, price stickiness depends on the treatment of sales. Guimaraes and Sheedy (2011) build a DSGE model with sales to examine whether monetary policy matters when normal prices are relatively sticky amid frequent price changes due to sales. Their initial model has two household types: loyal customers who have low price elasticity and bargain hunters who are very sensitive to price changes. They compare the results with a standard sticky price model without sales. In general, the real effects of monetary policy in both models are similar. The cumulative response of output in the model with sales is around 89 percent of that of the standard model. To accommodate the fact that sales are frequent in one sector and very rare in another, they also develop their model with two sectors: one sector features sales, while the other features standard pricing without sales. Again, the results are similar in comparison to the standard model. They conclude that sales do not matter for the analysis of the effect of monetary policy. 
Golosov and Lucas (2007) support the view that prices are more flexible in facing shocks. They construct a menu cost model and use micro data for calibration purposes. The data are the same as in BK (2004), covering seventy percent of the US CPI. The calibration is based on some moments of these micro data. Their model incorporates aggregate inflation shocks as well as idiosyncratic productivity shocks. The introduction of the idiosyncratic shocks mimics the frequency of price changes in the data, which cannot be explained by the aggregate shocks only. Their model predicts that the impulse responses of output, employment and prices are short-lived when facing these two shocks, that they are less persistent. Regarding prices, a positive aggregate shock that leads to a higher price will adjust the boundary of the firms that want to reset their prices. This asymmetric feature changes the number of firms that reset their prices; more firms want to increase their prices after the positive aggregate shocks. As a result, the aggregate price will increase, and this happens very quickly. On the other hand, the same shocks in the Calvo model do not generate similar impulse responses. The explanation is that the number of firms that want to change their prices is fixed, regardless of different conditions. As a result, the aggregate prices will not change as much as in the menu cost model.

As regards a suitable model to explain price behaviour, Bunn and Ellis (2012) examine this behaviour in the UK. In particular, they investigate the frequency of price changes, using two sources of data, to examine whether a time dependent or a state dependent model can better explain price behaviour. The first data set is monthly prices quoted to construct CPI and the Retail Price Index (RPI). The second type of data is weekly supermarket data. To observe whether the frequency of price changes is fixed over time, as implied by a time dependent model, they calculate the magnitude of changes with different samples of their micro data. They find that the strict time dependent model is inconsistent with the data, as the frequency of price changes varies over time. However, from the magnitude of price changes they also suggest that a single state dependent model, whether a menu cost model or a quadratic cost model such as that of Rothemberg (1982), may be unable to explain the price setting behaviour of most firms. Bunn and Ellis further construct hazard functions that are calculated from the ratio of share of price changes observed in the current period to share of price that has not changed in the previous period. If this function is flat, this implies consistency with the prediction of the time dependent models; if not, with those of state dependent models. Their hazard functions exhibit heterogeneity. For instance, the hazard function of goods prices is downward sloping, while that of service prices is relatively flat. In short, they conclude that the price setting behaviour is heterogeneous, so as a result no single existing price setting model can perfectly capture price behaviour at an economy-wide level.

Another paper that supports price stickiness is that of Boivin, Giannoni and Mihov (2009), hereafter BGM, who conduct their research on US consumer and producer price data. The data set used in this research is a balanced panel of 653 monthly series, including prices, for the period from 1976M1 to 2005M6. To examine the disaggregated prices, they employ the Factor Augmented Vector Auto Regressive (FAVAR) technique. This methodology is an extension of 
the VAR model, based on the work of Bernanke, Boivin and Eliasz (2005), hereafter BBE. With this technique, they disentangle the effect of a common component from an idiosyncratic component of the respective prices. The indicator data used to construct the latent factors in their FAVAR are the same as in BBE. However, for prices, BGM use disaggregated ones instead solely aggregated prices. Another difference is that BGM only use a two-step FAVAR².

They document that the volatility of aggregated prices measured by its standard deviation is related to the common component. The result is dramatically different when it comes to disaggregated prices. On average, most of the volatility in disaggregated prices is related to the idiosyncratic component. Overall, the disaggregated prices are more volatile than the aggregated prices and are less persistent. There is therefore a negative correlation between volatility and persistence, a finding which conflicts with what BK found.

BGM measure the persistence of common and idiosyncratic components of the prices using an AR model. They conclude that the persistence is highly varied across individual prices and mostly due to persistence in the common component. Meanwhile, the specific sectors display almost no persistence.

BGM also documents the response of the sectoral price level to a shock, specifically its own sector-specific shock, aggregate macroeconomic shock and monetary shock. The prices show different responses given different shocks. By and large, aggregate macroeconomic shocks have a significant and permanent influence on prices. Meanwhile, sector specific shocks only affect prices once and for all.

To analyse the effect of monetary policy shock, BGM apply an identification in their FAVAR system. They assume that the unobserved components or the latent factors do not respond contemporaneously to the change in the Fed Fund rate. The result shows the persistence of inflation across sectors. The prices tend to decline steadily for a couple of years following the monetary policy shock. Interestingly, the price puzzle that usually occurs in a VAR model disappears in this FAVAR model.

BGM can disentangle the source of a shock, whether it is macroeconomic, including monetary policy shocks, or sector specific shocks. The disaggregated prices respond sluggishly to the former shock; on the other hand, they tend to be flexible in response to the latter. This research therefore provides evidence for the fact that the volatility apparent in disaggregated prices as shown in BK is mostly related to a sector specific shock. It is not because of macroeconomic shocks, especially a monetary policy one.

Mumtaz, Zabczyk and Ellis (2009), hereafter MZE, follow the ideas of BGM and apply them to UK data. MZE use disaggregated consumer expenditure data and sixty sets of macroeconomic UK series data between 1977Q1 and 2006Q3. Technically, they enhance the

2 In Bernanke, Boivin and Eliasz (2005) two FAVAR models are employed: one step, which uses aBayesian technique, and two step, which uses aprincipal component to generate the factors. 
way of constructing the factors in FAVAR. In their baseline model, they construct them using all the data and without separating them into particular blocks. In their alternative model, they separate the data into certain blocks: real activity, inflation, money and asset prices. In order to do this, they apply sign restrictions using Bayesian estimation. For the benchmark, they also estimate a standard five-variable VAR with CPI inflation, GDP growth, M4 growth, the UK sterling exchange rate index (ERI) and Bank Rate. Their baseline model consists of eight factors and uses Cholesky decomposition ${ }^{3}$. Using this model, they find, in contrast to the BGM results, that the price puzzle still exists: the mean of CPI increases after a monetary contraction. The delay in the reaction of median inflation is almost two years. This is also different from the structural model of the UK, which shows a one to two year lag. Based on this, they check the robustness of the result using sign restriction in their FAVAR model. With this technique, the price puzzle disappears. Other than that, their findings are similar to those of BGM. The volatility for most disaggregated prices is mainly influenced by sector-specific shocks, rather than macroeconomic ones. Their findings also suggest that there is no relationship between persistence in the aggregate consumption deflator and the average persistence of the related component disaggregated deflator. Persistence in either aggregate or disaggregated prices is less influenced by sector-specific factors. In other words, the persistence in prices is mainly due to macroeconomic shocks, such as activity or policy changes.

\section{METHODOLOGY}

\subsection{Estimation Technique}

There are many methodologies for evaluating inflation at an aggregate level. Meanwhile, evaluation of inflation data at a disaggregated level requires a specific methodology. We employ a Factor Augmented Vector Autoregressive model, henceforth FAVAR, for various reasons. One main advantage is that FAVAR allows us to include many variables without worrying about the curse of dimensionality.

FAVAR models are Vector Autoregressive (VAR) ones that are augmented (A) by latent dynamic factor $(F)$ variables. Dynamic factor models are used when macro-econometricians face a degrees of freedom problem because the number of series exceeds the number of observations. The premise of dynamic factor models is that a large number of series can be represented by a few latent factors and idiosyncratic disturbances. These latent factors represent co-movement of the series and follow time series processes, usually VAR processes. Meanwhile, idiosyncratic disturbances are any factor that is specific to a single series. This also includes measurement errors of the series. Mathematically, a dynamic factor model is represented as follows:

3 Cholesky decomposition is a restriction to identify a VAR system. This restriction decomposes the residual in a triangular fashion that determines which shock affects another contemporaneously (Enders, 2004). 


$$
\begin{aligned}
& \mathrm{X}_{\mathrm{t}}=\lambda(L) \mathrm{F}_{\mathrm{t}}+\mathrm{e}_{\mathrm{t}} \\
& \mathrm{F}_{\mathrm{t}}=\Psi(L) \mathrm{F}_{\mathrm{t}-1}+\eta_{\mathrm{t}}
\end{aligned}
$$

$\mathrm{X}_{\mathrm{t}}$ is the vector of the $N$ series and $\mathrm{e}_{\mathrm{t}}$ are the idiosyncratic disturbances, so both are $N \mathrm{x}$ 1. There are $K$ latent factors $f_{t^{\prime}}$ so that $f_{t}$ and $\eta_{t}$ are $K \times 1$. As a result, $\lambda(L)$ and $\psi(L)$ are $N \times K$ and $K \times \mathrm{K}$ respectively. The $i^{\text {th }}$ lag polynomial $\lambda_{i}(L)$ is the dynamic factor loading of the $i^{\text {th }}$ series $X_{i t}$. The common component of the $i^{\text {th }}$ series $X_{i t}$ is. $\lambda_{i}(L) f_{t}$ The processes in equations (1) and (2) are assumed to be stationary. The idiosyncratic disturbance $e_{t}$ and the factor innovation $\eta_{t}$ are also assumed to be uncorrelated at all leads and lags, so that $E\left(e_{t} \eta_{t-j}^{\prime}\right)=0$ for all $j$, positive or negative.

The main issue in this framework is how to estimate the factors. According to Stock and Watson (2010), there are three generations of factor models. The first generation approach deals with the low dimension of series. It uses Maximum Likelihood and Kalman filter to generate the factors. These estimate optimal factors under the model, and with the assumed parameters. However, this entails nonlinear optimization, which restricts the number of parameters, and hence the number of series. The second generation approach deals with a large number of series and uses a non-parametric averaging method such as principal components and related methods. The third generation approach combines the consistent non-parametric estimation in the second generation with the first generation approach. It employs Bayesian methods to solve the dimensionality problem faced by the first generation approach.

This paper uses principal component analysis to estimate the factors, as adopted in BGM. Principal component analysis estimates the factors by identifying the patterns of a large number of series and expressing them based on their similarities. The factors generated summarize all the series, while capturing most of their variation. Once one has estimated the latent factors, one can use these for forecasting, using them as instrumental variables, or estimate a FAVAR model.

The FAVAR model was initially proposed by BBE (2005). This model follows a VAR model and uses observable variables and factors as variables in the VAR. The augmented term refers to the factors that are included in the VAR system. BBE (2005) apply two approaches in estimating their FAVAR: one step, which employs Bayesian techniques; and two steps, which uses principal component analysis to estimate the factors.

BBE (2005) use FAVAR to measure the effects of monetary policy, instead of the VAR that is commonly used to measure this effect. BBE (2005) note that there are three disadvantages of VAR models. First, a VAR model may not include all the variables used by the central banks or private sector. Due to the problem of degrees of freedom, a VAR model usually only employs a few variables. On the contrary, central banks or private agents usually watch a large number of indicators. As a result of the use of only a few variables, a shock to a policy variable can 
be contaminated. For instance, policy tightening is not purely an exogenous shock. It is partly because of anticipation of inflation pressure in the future that is not controlled for in a VAR model. This creates what is widely known as a price puzzle; monetary contraction is followed not by declining prices but rising ones (Sims, 1992). Second, a VAR model typically uses variables that are observable with some degree of error or that can only be approximated. For instance, real economic activity may be not precisely captured by observable variables such as production indices or real GDP. It is also justified by some assumptions such as measurement error, real time data and revisions. This is even true for variables such as CPI and GDP. Given this, we need an approach to capture these unobservable variables in a more comprehensive and precise way. The third caveat of VAR is that it can only generate a limited number of impulse responses of the variables, as only a few variables are included. Meanwhile, policy makers usually want to see the impulse response of many variables so that their decisions can be more comprehensive.

BBE (2005) propose FAVAR to address these drawbacks. By employing a few factors that can summarize a large number of series, it can address the degree of freedom problem. These factors also solve the non-observable problem by using many variables that approximate the unobservable ones. The third problem is also answered; by employing many variables, impulse responses of many variables are provided to the policy makers. A FAVAR model can be formulated as follows:

$$
\left[\begin{array}{c}
\mathrm{F}_{\mathrm{t}} \\
\mathrm{Y}_{\mathrm{t}}
\end{array}\right]=\Phi(L)\left[\begin{array}{l}
\mathrm{F}_{\mathrm{t}-1} \\
\mathrm{Y}_{\mathrm{t}-1}
\end{array}\right]+\mathrm{v}_{t}
$$

where $F_{t}$ is the $K \times 1$ vector of unobservable factors and $Y_{t}$ is the $M \times 1$ vector of observable variables. The error term $v_{t}$ is i.i.d. with mean zero. Equation (3) is a reduced form of a VAR equation with $\Phi(L)$ as the lag polynomial. A FAVAR model refers to this equation. It nests a standard VAR but is augmented with additional information contained in the factors. If the true system is a FAVAR but we estimate a standard VAR, which is equation (3) consisting of $Y_{t}$ only, we end up with spurious estimators.

However, we cannot solve equation (3) directly without knowing the unobservable factors. We need to generate them. As already mentioned, the factors are the summaries of a large number of series. Hence, we can generate the factors from those series. Suppose we have a vector of informational variables $X_{t}, N \times 1$, where $N$ is the number of series included. The relationship between the series $\left(X_{t}\right)$, the factors $\left(F_{t}\right)$, and the observable variables can be formulated as follows:

$$
X_{t}=\Lambda\left[\begin{array}{l}
F_{t} \\
Y_{t}
\end{array}\right]+e_{t}
$$


where $\Lambda$ is the $N \times(K+1)$ matrix of the loading factors. The first part of the right hand side of this equation is the common component of the series and the last part $\left(e_{t}\right)$ is the $N \times 1$ matrix of the idiosyncratic component. The series of common components are uncorrelated with those of idiosyncratic components. Equation (4) allows us to extract the factors, given the indicator series and the observable variables. The general term of equation (4) may involve the lags of the factors, as in equation (2) of the dynamic factor model.

The shocks imposed on these two components are macroeconomic shocks and sector specific shocks respectively. By definition, a sector specific shock refers to a shock that is only imposed on one series. For example, a shock to a certain world commodity price might only influence a certain domestic commodity price. At least it should not influence other domestic commodity prices directly or significantly. Meanwhile, a macroeconomic shock could influence all prices, hence it is called a common shock. A shock to a macroeconomic variable such as the exchange rate or a policy change could influence the movement of all individual prices.

As in BGM, we shall focus on the behavior of disaggregated prices. Hence we shall involve disaggregated price series in $X_{t}$. In addition to this, we are interested in the effect of monetary policy shock on the disaggregated price series. For that, we replace $Y_{t}$ with the interest rate $\left(R_{\mathrm{t}}\right)$ as the observable variable. We follow a two-step approach, as in BGM. First, we extract the series using principal component analysis to obtain the latent or common factors $\mathrm{F}_{\mathrm{t}}$. In the second step, we add policy rate $R_{\mathrm{t}}$ and estimate the system VAR as in equation (3). We follow recursive identification with the order $\left[\mathrm{F}_{\mathrm{t}^{\prime}} R_{\mathrm{t}}\right]$; with this identification the interest rate $R_{\mathrm{t}}$ is influenced contemporaneously by the common factors $\mathrm{F}_{\mathrm{t}}$. Meanwhile, the common factors react to the interest rate with a lag. We can interpret the last equation of the VAR as a contemporaneous interest rate rule.

We follow Bai and Ng's (2002) information criteria to determine how many factors are properly included. This method is suitable for a large number of series and observations. This method also allows for both limited time series and cross-section dependence, and for heteroskedasticity in the time series and cross section in the idiosyncratic component. For the lags, we employ information criteria commonly used to estimate a VAR model.

\subsection{Data}

The data employed in some research consist of data for individual prices that are collected and used to calculate CPI; these are called micro data. We do not employ these micro data, but follow BGM, who use disaggregated of CPI. We use monthly data from 2002 to 2011, which are based on the 2007 cost of living survey. We back cast the 2007 data to the 2002 base year, based on month-to-month growth of the data of the 2002 base. Given the two cost of living surveys (2002 and 2007) during the period of estimation, we do not use all the disaggregated prices, but all price data in the 2007 base that are also present in the 2002 base. Unlike BGM, 
we group the series into the CPI that includes all individual, core and non-core prices. These generate monthly headline inflation, core inflation and non-core inflation respectively. The reason for this is that we can identify the impulse responses of these groups. In particular, we can observe the impulse responses of core inflation in facing monetary policy shocks. By definition, core inflation is influenced more by fundamental factors such as monetary policy. Overall, the disaggregated prices included cover around 96 percent of the components of the $\mathrm{CPI}$, comprising 63.6 percent of core prices and 32.4 percent of non-core prices.

In addition to disaggregated prices we also use certain indicators to construct the factors. These indicators include demand factors such as sales data; production factors such as the production index; exports and imports; monetary data; world commodity prices; interest rates and exchange rates. Some data are interpolated if the available data are quarterly. These include real GDP and its components. We include this combination of disaggregated CPI and indicators to construct the latent factors using Principal Component Analysis in the spirit of equation (5.8). In total we use data on 663 individual prices and 92 indicators, with 118 observations within the period 2002M3 to 2011M12. For comparison, BGM use 111 indicators, 154 PPI series, 194 PCE deflator series and 194 PCE deflator quantities; in total 653 series, with 353 observations for each one.

We seasonally adjust the data for the individual prices and transform many of them. The transformations include the difference of the logarithms of the variables and first differences. Some of the data are not transformed.

\section{RESULT AND ANALYSIS}

We run the estimations using the MatLab code created by BGM with some modifications to permit consistency with our case. For the information criteria in Bai and $\mathrm{Ng}$ (2002) we use the MatLab code created by Schumacher and Breitung (2008). Bai and Ng's (2002) criteria shows if we only include price data, the factor are only one. If we only include the indicators, we obtain four factors to represent them. However, if we include both the price data and the indicator data we obtain one factor. Our guess is that this is because of the domination of price data. We have data on 663 prices and 92 indicators. This domination is also evident when we estimate only certain groups of prices. If we only use one factor, that factor may represent the prices closely, but may display no link with other indicators. Based on this, we have chosen five factors. As a result, in the system of equations (5.7) and (5.8) we have five factors and one observable variable.

The Likelihood Ratio test (LR), the Final Prediction Error test (FPE) and the Akaike Information Criterion (AIC) point to 4 lags. The Schwarz Criterion (SC) and Hannan-Quin (HQ) show 2 lags. We choose 4 lags based on the result of these five criteria. Moreover, with 4 lags we can capture the dynamics between quarters. However, we also estimate the model using a 
different number of factors for the sake of robustness. We try 4, 6 and 8 factors with four lags. For the lags, we also try 2 lags with five factors; the results are not significantly different. We do not try one lag since no information criteria justify the use of only one in this estimation.

Given the formulation of equation (5), we can analyze inflation behavior at a disaggregated level. Equation (5) implies:

$$
\pi_{i t}=\lambda_{i}^{\prime} \mathrm{C}_{\mathrm{t}}+e_{i t}
$$

This equation states that inflation $\left(\pi_{i t}\right)$ can be explained by its common component $\left(\lambda_{i}{ }_{i} C_{t}\right)$ and its sector specific component $\left(e_{i t}\right)$. FAVAR allows us to separate these two components of inflation and analyze their behavior.

\subsection{Volatility and the Persistence of Inflation}

First, we compare the statistics of aggregate and disaggregated inflation in terms of volatility and persistence. These two statistics are fundamental in assessing price behavior, in particular as to whether prices are more rigid or more flexible and how they respond to shocks. This behavior is important for the monetary policy aspect; in particular, it can give illuminate the role of monetary policy in inflation.

Table 1 summarizes these two statistics. Using standard deviation as a proxy of volatility, we find that the volatility of disaggregated inflation is higher than that of aggregate inflation. The standard deviation of CPI inflation is 0.791 , while that of disaggregated CPI inflation is 2.453 on average. This can be explained by the fact that sector specific volatilities tend to cancel each other out, so the volatilities in aggregate inflation decline. The main factor in inflation volatility is the volatility of the sector specifics. This is a fact in both aggregate and disaggregated inflation. $R^{2}$ statistics, which measure the ratio of variance of the common component to that of inflation, show that the common components only explain less than 50 percent of the volatility of inflation. If we compare the $R^{2}$ statistics for core and non-core inflation, they are higher for core inflation. This implies that the common component plays a greater role in core inflation than in non-core inflation volatility. In other words, the shocks to macroeconomic variables play a more important role in core inflation volatility than non-core inflation volatility.

Table 1 also shows heterogeneity in terms of volatility across the inflation sector. The range is from 0.003 to 25.809 percent, with an average of 2.453 percent. If we examine the group of core and non-core inflation, the volatility is higher in non-core inflation, as expected. This relates to the inflation rate for food, transportation and cigarettes (which are among the administered prices). Increased excise on cigarettes and reductions in fuel subsidy in the period of investigation are the causes. 


\begin{tabular}{|c|c|c|c|c|c|c|c|}
\hline \multicolumn{8}{|c|}{$\begin{array}{l}\text { Table } 1 \\
\text { Volatility and Persistence of Monthly Inflation Series }\end{array}$} \\
\hline & \multicolumn{3}{|c|}{ Standard Deviation (in percent) } & \multirow{2}{*}{$\mathbf{R}^{2}$} & \multicolumn{3}{|c|}{ Persistence } \\
\hline & Inflation & $\begin{array}{c}\text { Common } \\
\text { Components }\end{array}$ & $\begin{array}{l}\text { Sector } \\
\text { Specifics }\end{array}$ & & Inflation & $\begin{array}{c}\text { Common } \\
\text { Components }\end{array}$ & $\begin{array}{l}\text { Sector } \\
\text { Specifics }\end{array}$ \\
\hline \multicolumn{8}{|c|}{ Aggregated CPI } \\
\hline $\mathrm{CPI}$ & 0.791 & 0.251 & 0.750 & 0.101 & 0.234 & 0.855 & 0.134 \\
\hline Core & 0.308 & 0.137 & 0.276 & 0.198 & 0.358 & 0.833 & 0.567 \\
\hline Vol. Food & 1.345 & 0.481 & 1.256 & 0.128 & 0.196 & 0.728 & 0.906 \\
\hline Adm. Prices & 2.421 & 0.674 & 2.325 & 0.078 & 0.085 & 0.951 & 0.893 \\
\hline \multicolumn{8}{|c|}{ Disaggregated CPI } \\
\hline - Average & 2.453 & 0.837 & 2.256 & 0.202 & 0.003 & 0.430 & -0.119 \\
\hline - Median & 1.260 & 0.529 & 1.100 & 0.153 & 0.034 & 0.508 & -0.095 \\
\hline - Minimum & 0.003 & 0.000 & 0.003 & 0.008 & -2.192 & -1.043 & -1.590 \\
\hline - Maximum & 25.809 & 6.914 & 24.991 & 0.866 & 0.853 & 0.897 & 0.724 \\
\hline $\begin{array}{l}\text { - Standard } \\
\text { deviation }\end{array}$ & 2.967 & 0.894 & 2.869 & 0.167 & 0.396 & 0.345 & 0.338 \\
\hline \multicolumn{8}{|c|}{ Disaggregated-Core } \\
\hline - Average & 1.271 & 0.511 & 1.132 & 0.231 & 0.114 & 0.459 & -0.038 \\
\hline - Median & 0.814 & 0.364 & 0.692 & 0.195 & 0.120 & 0.541 & -0.019 \\
\hline - Minimum & 0.053 & 0.030 & 0.044 & 0.008 & -1.291 & -0.870 & -0.970 \\
\hline - Maximum & 7.489 & 3.315 & 7.446 & 0.866 & 0.770 & 0.897 & 0.642 \\
\hline $\begin{array}{l}\text { - Standard } \\
\text { deviation }\end{array}$ & 1.244 & 0.455 & 1.188 & 1.188 & 0.308 & 0.341 & 0.284 \\
\hline \multicolumn{8}{|c|}{ Disaggregated-Non Core } \\
\hline - Average & 4.309 & 1.347 & 4.020 & 0.155 & -0.171 & 0.384 & -0.247 \\
\hline - Median & 3.226 & 1.109 & 2.968 & 0.094 & -0.101 & 0.437 & -0.230 \\
\hline - Minimum & 0.003 & 0.000 & 0.003 & 0.008 & -2.192 & -1.043 & -1.590 \\
\hline - Maximum & 25.809 & 6.914 & 24.991 & 0.832 & 0.853 & 0.862 & 0.724 \\
\hline $\begin{array}{l}\text { - Standard } \\
\text { deviation }\end{array}$ & 3.819 & 1.142 & 3.725 & 0.158 & 0.453 & 0.347 & 0.375 \\
\hline
\end{tabular}

The strong relationship between the volatility of inflation and its sector specific volatilities are also exhibited in table 2. The correlation between standard deviation of inflation and its sector specific is almost one. This happens to CPI and core and non-core inflation, as shown in Table 3 and Table 4.

Sector specific volatility can be interpreted in two ways. First, it is a reflection of structural disturbances. Second, sector specific volatility could also be interpreted as measurement or sampling error in each price sector. To clean up the individual price from this error is difficult. However, the empirical framework adopted here is suitable for this condition, as mentioned in BGM (p.358): "It is important to note, though, that the empirical framework adopted here is 
particularly well suited to characterize the effects of aggregate disturbances on disaggregated price series in the presence of measurement error, to the extent that such errors are series specific. In this case, measurement error does generally not distort the estimates of the common components and the estimated effects of aggregate disturbances, even in the extreme situation in which the sector specific components of inflation are entirely driven by measurement error".

We regress the volatility of the idiosyncratic component on that of the common component, and find a positive and robust relationship between the two. The gradient is 2.945 , significant at one percent level. The $R^{2}$ is also high at 0.71 , implying a high goodness of fit. This relationship implies that the sector specific volatility is influenced strongly by the common components that reflect the structural disturbances. Had the volatility of sector specific been mostly influenced by measurement errors, it would have been difficult to find this strong relationship.

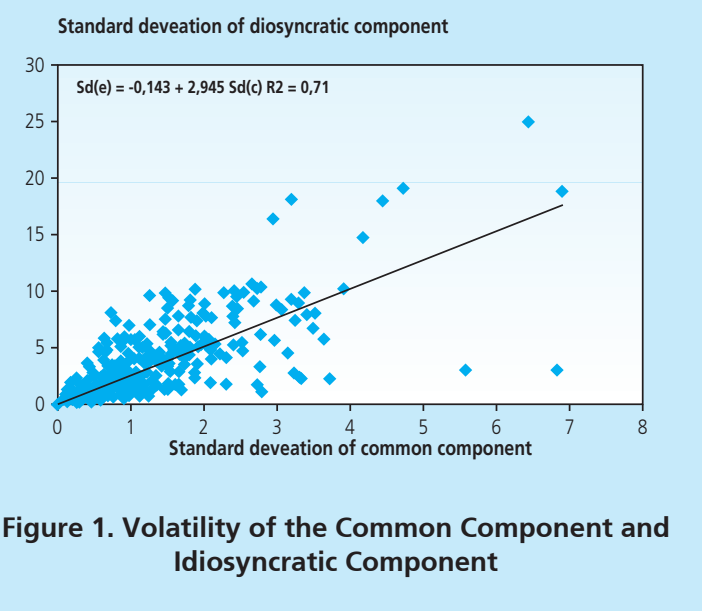

We also compute the inflation persistence using an AR model as in BGM as follows.

$$
w_{t}=\rho(L) w_{t-1}+\varepsilon_{t}
$$

where $w_{t}$ refers to the individual price series, their common component and their specific component. We use 4 lags to be in line with the lags chosen by the information criteria in FAVAR. The degree of persistence is measured here by the sum of the coefficients of all lags. Table 1 show that the inflation persistence of aggregate inflation is higher than for disaggregated inflation. This implies that aggregate inflation is more rigid than disaggregated inflation. At the aggregate level, core inflation is more persistent than non-core inflation, at 0.358 compared to 0.196 and 0.085 respectively. Meanwhile, at a disaggregated level, on average inflation shows almost no persistence. 
According to the Calvo models, price stickiness implies a negative relationship between volatility and persistence. This model predicts if the prices are less volatile or stickier, they are less responsive to exogenous shocks. As a result, they become more persistent. Tables 2, 3, and 4 show the coefficients of correlation between inflation persistence and the standard deviation (as a proxy of volatility of inflation). We find the coefficient is negative for CPI, core, and non-core inflation, as predicted by Calvo models. Even for CPI and non-core inflation, the coefficient correlation is strongly negative: -0.558 and -0.538 respectively. Meanwhile, it is -0.372 for core inflation. This finding is in line with the findings of BGM and does not support the findings of BK.

\begin{tabular}{|c|c|c|c|c|c|c|c|}
\hline \multicolumn{8}{|c|}{$\begin{array}{c}\text { Table } 2 \\
\text { Coefficient Correlation for the Volatility and Persistence of CPI Inflation }\end{array}$} \\
\hline \multirow{2}{*}{$\mathrm{CPI}$} & & \multicolumn{3}{|c|}{ Standard Deviation } & \multicolumn{3}{|c|}{ Persistence } \\
\hline & & Inflation & $\begin{array}{l}\text { Common } \\
\text { Component }\end{array}$ & $\begin{array}{l}\text { Sector } \\
\text { Specific }\end{array}$ & Inflation & $\begin{array}{l}\text { Common } \\
\text { Component }\end{array}$ & $\begin{array}{l}\text { Sector } \\
\text { Specific }\end{array}$ \\
\hline \multirow{3}{*}{ 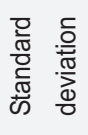 } & Inflation & 1 & 0.840 & 0.995 & -0.558 & -0.168 & -0.462 \\
\hline & \multicolumn{2}{|c|}{ Common component } & 1 & 0.785 & -0.438 & -0.296 & -0.364 \\
\hline & \multicolumn{2}{|c|}{ Sector specific } & & 1 & -0.561 & -0.143 & -0.465 \\
\hline \multirow{3}{*}{ 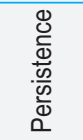 } & \multicolumn{2}{|l|}{ Inflation } & & & 1 & 0.363 & 0.831 \\
\hline & \multicolumn{2}{|c|}{ Common component } & & & & 1 & 0.102 \\
\hline & \multicolumn{2}{|c|}{ Sector specific } & & & & & 1 \\
\hline
\end{tabular}

According to the Calvo models, price stickiness implies a negative relationship between volatility and persistence. This model predicts that if prices are less volatile or stickier, they are less responsive to exogenous shocks. As a result, they become more persistent. Tables 2, 3 and 4 show the coefficients of correlation between inflation persistence and the standard deviation (as a proxy of volatility of inflation). We find that the coefficient is negative for CPI and core and non-core inflation, as predicted by the Calvo models. Even for CPI and non-core inflation,

\begin{tabular}{|c|c|c|c|c|c|c|c|}
\hline \multicolumn{8}{|c|}{$\begin{array}{c}\text { Table } 3 \\
\text { Coefficient Correlation for the Volatility and Persistence of Core Inflation }\end{array}$} \\
\hline \multirow[b]{2}{*}{ Core } & & \multicolumn{3}{|c|}{ Standard Deviation } & \multicolumn{3}{|c|}{ Persistence } \\
\hline & & Inflation & $\begin{array}{l}\text { Common } \\
\text { Component }\end{array}$ & $\begin{array}{l}\text { Sector } \\
\text { Specific }\end{array}$ & Inflation & $\begin{array}{l}\text { Common } \\
\text { Component }\end{array}$ & $\begin{array}{l}\text { Sector } \\
\text { Specific }\end{array}$ \\
\hline \multirow{3}{*}{ 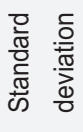 } & Inflation & 1 & 0.773 & 0.990 & -0.372 & -0.044 & -0.244 \\
\hline & \multicolumn{2}{|c|}{ Common component } & 1 & 0.682 & -0.256 & -0.206 & -0.158 \\
\hline & \multicolumn{2}{|c|}{ Sector specific } & & 1 & -0.371 & -0.005 & -0.247 \\
\hline \multirow{3}{*}{ 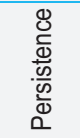 } & \multicolumn{2}{|l|}{ Inflation } & & & 1 & 0.493 & 0.733 \\
\hline & \multicolumn{2}{|c|}{ Common component } & & & & 1 & 0.137 \\
\hline & \multicolumn{2}{|c|}{ Sector specific } & & & & & 1 \\
\hline
\end{tabular}


the coefficient correlation is strongly negative: -0.558 and -0.538 respectively. Meanwhile, it is -0.372 for core inflation. This finding is in line with the findings of BGM and does not support the findings of BK.

\begin{tabular}{|c|c|c|c|c|c|c|c|}
\hline \multicolumn{8}{|c|}{$\begin{array}{l}\text { Table } 4 \\
\text { Coefficient Correlation for the Volatility \& Persistence of Non-Core Inflation }\end{array}$} \\
\hline \multirow[b]{2}{*}{ Non Core } & & \multicolumn{3}{|c|}{ Standard Deviation } & \multicolumn{3}{|c|}{ Persistence } \\
\hline & & Inflation & $\begin{array}{l}\text { Common } \\
\text { Component }\end{array}$ & $\begin{array}{l}\text { Sector } \\
\text { Specific }\end{array}$ & Inflation & $\begin{array}{l}\text { Common } \\
\text { Component }\end{array}$ & $\begin{array}{l}\text { Sector } \\
\text { Specific }\end{array}$ \\
\hline \multirow{3}{*}{ 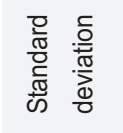 } & Inflation & 1 & 0.800 & 0.994 & -0.538 & -0.207 & -0.465 \\
\hline & \multicolumn{2}{|c|}{ Common component } & 1 & 0.735 & -0.383 & -0.372 & -0.340 \\
\hline & \multicolumn{2}{|c|}{ Sector specific } & & 1 & -0.546 & -0.178 & -0.471 \\
\hline \multirow{3}{*}{ 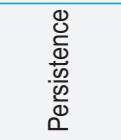 } & \multicolumn{2}{|l|}{ Inflation } & & & 1 & 0.219 & 0.879 \\
\hline & \multicolumn{2}{|c|}{ Common component } & & & & 1 & 0.011 \\
\hline & \multicolumn{2}{|c|}{ Sector specific } & & & & & 1 \\
\hline
\end{tabular}

If we examine common components and sector specifics, there is also a negative relationship between volatility and persistence. The strength of the relationship is higher for CPI and non-core inflation. If we compare common component and sector specifics, the coefficient correlation is more negative for the latter. This is in contrast to what BGM find based on the US data. They find that the negative correlation is stronger for the common component. Based on their findings, BGM argue that this makes the Calvo models more successful in describing volatility and persistence inflation in response to macroeconomic shocks rather than sector specific shocks. Meanwhile, in our case, the Calvo models seem suitable for explaining the volatility and persistence of Indonesian inflation, but might be more suitable for explaining the volatility and inflation persistence in response to sector specific shocks. Further research is needed to address this issue.

\subsection{Impulse Responses of Prices to Macroeconomic and Sector Specific Shocks}

We construct an AR model of the two components of inflation: the common component () and the sector specific component (). We use 4 lags in order to be consistent with the lags of the FAVAR framework in this exercise. We impose shocks of minus one standard deviation, and observe the impulse responses of disaggregated prices in terms of their common and sector specific components. We interpret these as the impulse responses of disaggregated prices to the macroeconomic and idiosyncratic shocks. 


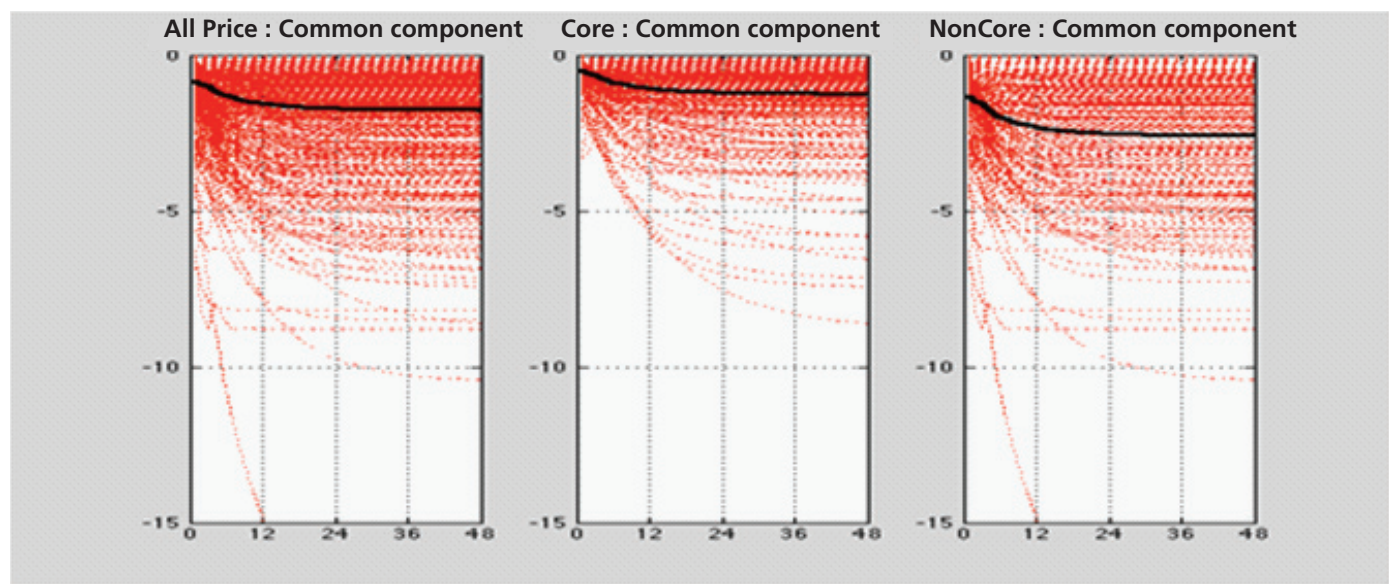

Figure 2.

Impulse Responses of Prices to Macroeconomic Shocks

Figure 2 shows the impulse responses of prices (in percent) to macroeconomic shocks, measured by a minus one standard deviation shock to its common component. The figures consist of three panels: the first panel shows the responses of all disaggregated prices, the second panel the responses of disaggregated core prices and the third panel the responses of disaggregated non-core prices. The red curves are the impulse responses of disaggregated prices and the solid black curve is the average of the impulse responses. Here, the weight of each price is equal, and is not based on the actual expenditure weights.

The panels show the heterogeneity of price behavior, given a macroeconomic shock. The magnitudes and the periods of responses are different across prices. The average impulse responses show that most of the prices fall moderately in the first few months and continue to fall slowly until they reach their new equilibrium. The speeds of adjustment also exhibit heterogeneity. Some prices reach their new equilibrium in less than 12 months, while others need more than 12 months to reach this. Comparing the core and non-core prices, the core ones are less responsive than the non-core. On average, the magnitudes of the impulse responses of core prices are less than those of non-core prices. The speed of adjustment of non-core prices is also more heterogeneous.

Figure 3 shows the impulse responses of disaggregated prices (in percent) to sector specific shocks. Unlike the previous figure, this figure shows the immediate responses of disaggregated prices to the sector specific shocks, with prices falling immediately to their new equilibrium in the first few months after the shocks. The impulse responses also exhibit heterogeneity among the prices. Some prices deviate by less than five percent, while others deviate more than five percent from their initial level. As in the previous figure, the non-core prices are also more responsive. The magnitude of their impulse responses to sector specific shocks is on average higher than that for the core prices. 


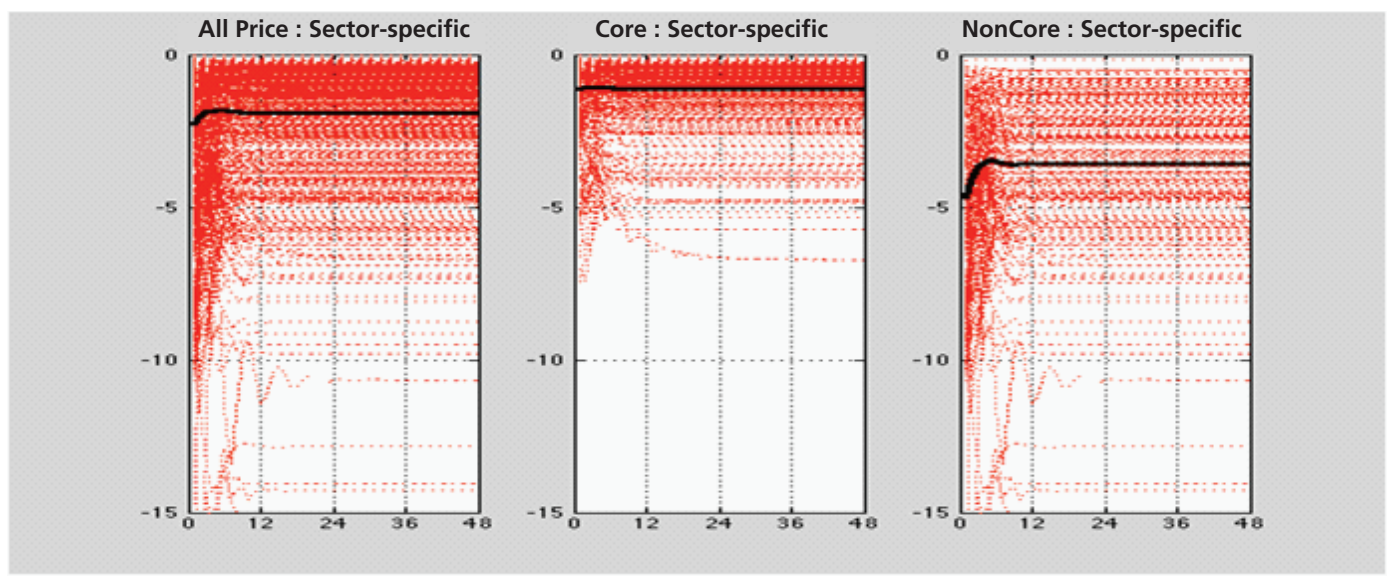

Figure 3.

Impulse Responses of Prices to Sector Specific Shocks

A comparison between figures 2 and 3 illuminates the difference in the speed of adjustment of prices to different types of shocks, with this speed reflecting how flexible the prices are. Both macroeconomic and sector specific shocks affect disaggregated prices immediately. On average, disaggregated prices are more flexible in the face of sector specific shocks, as the new equilibrium of prices is reached immediately. The magnitudes of impulse responses are also greater. In contrast, disaggregated prices respond more sluggishly to macroeconomic shocks, still responding gradually after the macroeconomic shocks for several periods until approaching their new equilibria. The differences show that the source of shocks matters.

This finding is also found in BGM. Prices in the US are sluggish in response to macroeconomic disturbances. The difference from the Indonesia data is that there are a greater number of prices that are more flexible to macroeconomic disturbances. Figure 1 shows that the disaggregated prices fall immediately in the first few months. After that, the prices are sluggish as the impulse responses move slowly. In general, prices in Indonesia are more flexible than in the US in response to macroeconomic shocks. One possible explanation for this is that Indonesia as a small open economy is more exposed to fluctuations in the world economy than the US. The trade ratio of Indonesia, measured by the sum of exports and imports to GDP, is higher than for the US in the period of estimation. Its exchange rate also fluctuates following the dynamics of the world economy. Meanwhile, since January 1985, the nominal effective exchange rate of the USD has displayed low volatility. The higher volatility of the rupiah, a macroeconomic variable, may be reflected in prices that are also more flexible, given the exchange rate pass through to prices. 


\subsection{Impulse Responses of Prices to Policy Rate Shocks}

In the previous sections, we have compared the volatility and persistence of disaggregated prices and evaluated the impulse responses of disaggregated prices to sector specific and macroeconomic shocks. Macroeconomic shocks represent disturbances that happen to a group of macroeconomic variables. These involve a shock to a macroeconomic variable such as the exchange rate or interest rate. Hence the impulse responses generated are not caused by a specific shock such as a change in the policy interest rate. We cannot disentangle macroeconomic shocks into a set of specific shocks.

Here, we need to know the behavior of prices given a specific shock, in particular monetary policy shocks, to observe the role of monetary policy. In order to do this, we impose a shock on the observable variable $\left(R_{t}\right)$ in equations (3) and (4). We use policy rate as a proxy for monetary policy and identify the monetary policy shock by assuming that policy rates respond contemporaneously to a shock to the latent factors $\left(F_{t}\right)$. In contrast, the latent factors can respond to an unanticipated policy rate shock after a month. There is a lag between an unanticipated policy rate shock and the response of the latent factors. The FAVAR framework then allows us to examine the impulse response of disaggregated prices to an unanticipated policy rate shock.

This unanticipated shock is a 25 basis point policy rate increase, which imposes monetary policy contraction. Theoretically, the inflation rate should decrease following monetary contraction. However, we find different results. Figure 4 shows the impulse responses of disaggregated prices (in percent) for all prices, core and non-core.
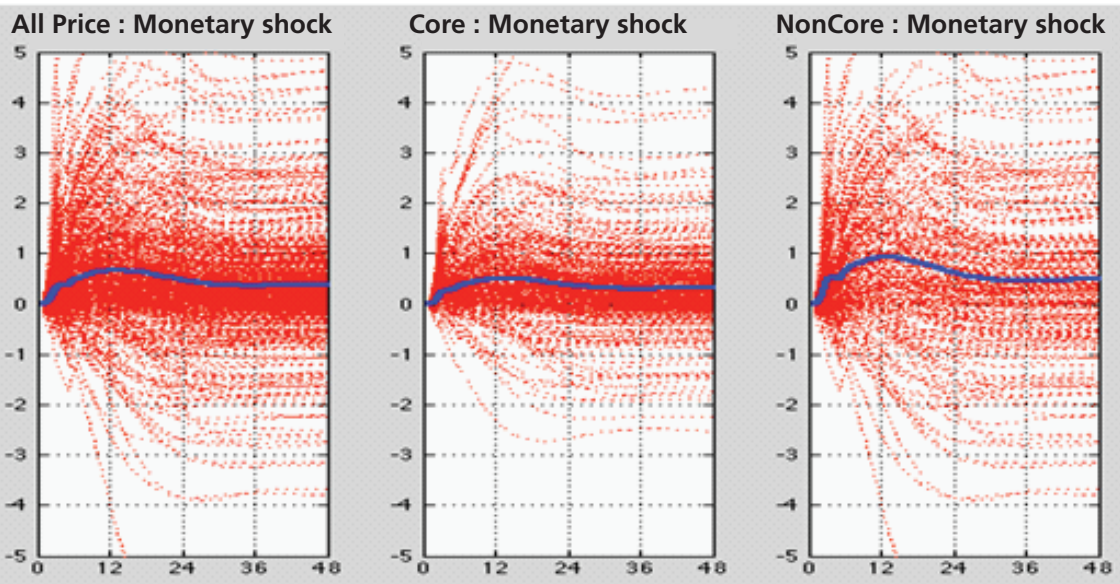

Figure 4.

Impulse Responses of Prices to Policy Rate Shocks 
We again find heterogeneity of the responses, not only in terms of magnitude and speed of adjustment, but also in direction. Some prices decrease, but others increase. If we give an equal weight to each individual price, on average the responses increase slightly. If we compare the responses of core and non-core prices, we find that the core prices are less responsive. Compared to what BGM found based on the US data, the impulse responses are similar. Some prices decrease following monetary policy contraction. The difference is that in BGM the average of impulse responses is negative for the US data, while we find, on average, slightly positive impulse responses for the Indonesian data. In other words, Indonesia displays a greater price puzzle. In addition, this puzzle is persistent; the average impulse responses do not decrease in the long run.

There are some possible explanations for the price puzzle. From a modelling perspective, Sims (1992) suggests that misspecification in VAR models, in particular the omission variable problem, is the cause. Comparing OECD countries, he finds that France and Japan experience a price puzzle, and that this positive relationship between monetary policy shock (contraction) and price is significant and persistent. One possible explanation is that the policy makers have anticipated the future inflation and consequently contract the monetary policy variable. As predicted, prices increase, though less than if the policy rate had not been raised. This anticipated inflation is not accommodated in the model, so generates a price puzzle. Furthermore, a policy rate increase may signal to firms that inflation would otherwise rise more than the firms had anticipated. And if price adjustment costs are convex (as in Rotemberg, 1982), firms may already have embarked on a gradual sequence of price increases, from which deflation will take time.

Christiano, Eichenbaum and Evans (1994, 1996), henceforth CEE, propose that commodity prices be included in VAR models. These prices can capture future inflation and supply shocks and therefore the omission problem can be avoided. The order is output, aggregate price, commodity price and policy rate. This can solve the puzzle for the full sample of 1960-1990 US data. Balke and Emery (1994) replicate the VAR model of CEE (1994) but with a different period. They demonstrate that the puzzle is not resolved before the 1980s and test other variables to solve the puzzle. One variable that can solve it is the spread of short and long-term interest rates. Including this variable can solve the puzzle in the pre-1980s.

When the FAVAR technique is applied, the omission problem should be avoided or the possibility of its presence should be reduced, as many variables are included. Hence, there could be other explanations for this puzzle.

Theoretically, there are two main effects of monetary policy on the economy: demand side effects and supply side effects. The study of the monetary policy transmission mechanism is mostly related to the former. There are various channels already studied which relate to the demand effect: the interest rate channel, the exchange rate channel, the expectation channel, the credit channel (bank lending and balance sheet) and the asset price channel. Generally, 
the research concludes that monetary contraction will reduce aggregate demand and that the economy will end up with lower price levels. The supply side views support the notion that the effect of monetary changes will affect the cost of production, hence it is also called the cost-side effect. Unlike the demand effect, which shifts aggregate demand, the cost-side effect shifts aggregate supply. In the case of monetary contraction, both aggregate demand and aggregate supply will shift to the left. Whether the price will be higher or lower depends on the dominance of one of these two effects. The price puzzle that occurred in our case may not have been because of misspecification problems, but because of the economic conditions in Indonesia during the estimation period. This may explain the dominance of supply side effects.

There are some possible explanations for such supply side effects. Interest rate increases may raise the cost of production through tightened credit conditions. For instance, firms face costs such as wage payments, which they incur before selling their products. As they finance these costs through credit, tight monetary policy worsens their credit condition. As a result, the firms reduce their labour demand and hence their production. Moreover, the monetary contraction may exacerbate the supply side effect through a reduction in demand. The firms may face internal financing difficulties as fewer products are sold or there are increasing inventory costs and account receivables, so turn to external financing (Barth and Ramey, 2001). Both direct and indirect effects compel the firms to increase the price of their products. Another explanation is market concentration. When demand decreases as a result of monetary contraction, many firms may exit the market. The fewer firms who stay in the market may enjoy increased oligopoly power and raise their prices.

From the impulse response above we notice that not all price series exhibit a puzzle. Many prices also decrease following monetary contraction. This heterogeneity suggests that different effects work dominantly on different prices. In the subsequent sections, we elaborate on some estimates to establish whether the puzzle in terms of aggregate prices diminishes or even disappears.

\subsection{Impulse Responses of Prices to Deposit and Loan Rate Shocks}

Regarding monetary policy shock, we have used the policy rate as the proxy of monetary policy. We imposed the shock on the policy rate to picture the monetary policy contraction. We now try other observable variables: the three month deposit rate and working capital loan rate. The deposit rate and loan rate are two representatives of market rates, which are closer to the real sector. Generally, the changes in policy rate should be transmitted to these retail rates.

We impose a 25 bps increase on the deposit and the loan rates, which reflects monetary policy contraction. The pictures are similar in terms of heterogeneity, as shown in figures 4 , 5 and 6 . Some prices rise following the increase in the deposit or loan rate while others fall. However, in terms of average prices, the pictures are quite different. In the two last figures, the 

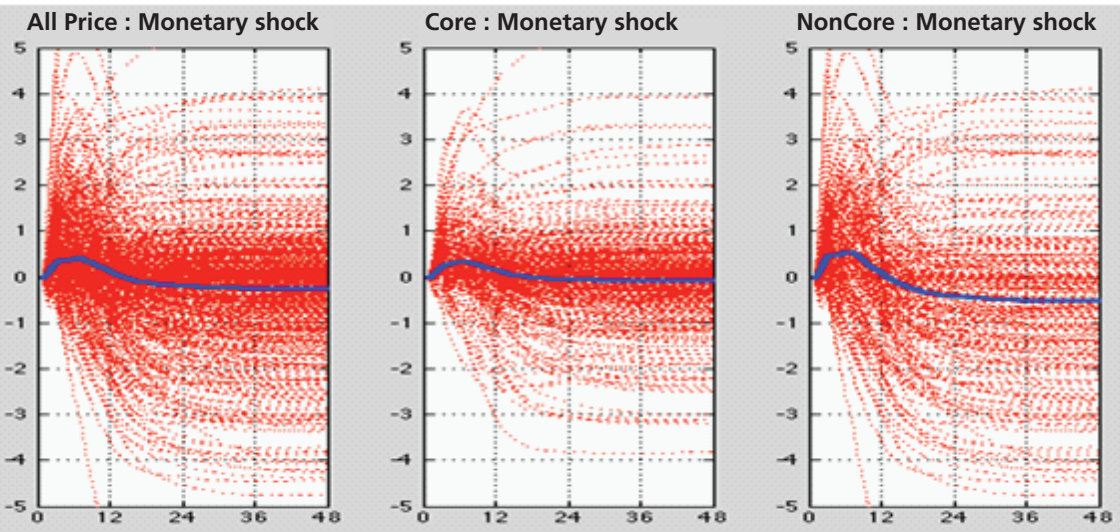

Figure 5.

Impulse Responses of Prices to Deposit Rate Shocks

impulse responses show that prices rise after the increase in the deposit and loan rates, up to twelve months later. After that, on average, prices fall. This means that after twelve months more prices fall following the increase in deposit and loan rates. The puzzle is no longer persistent.

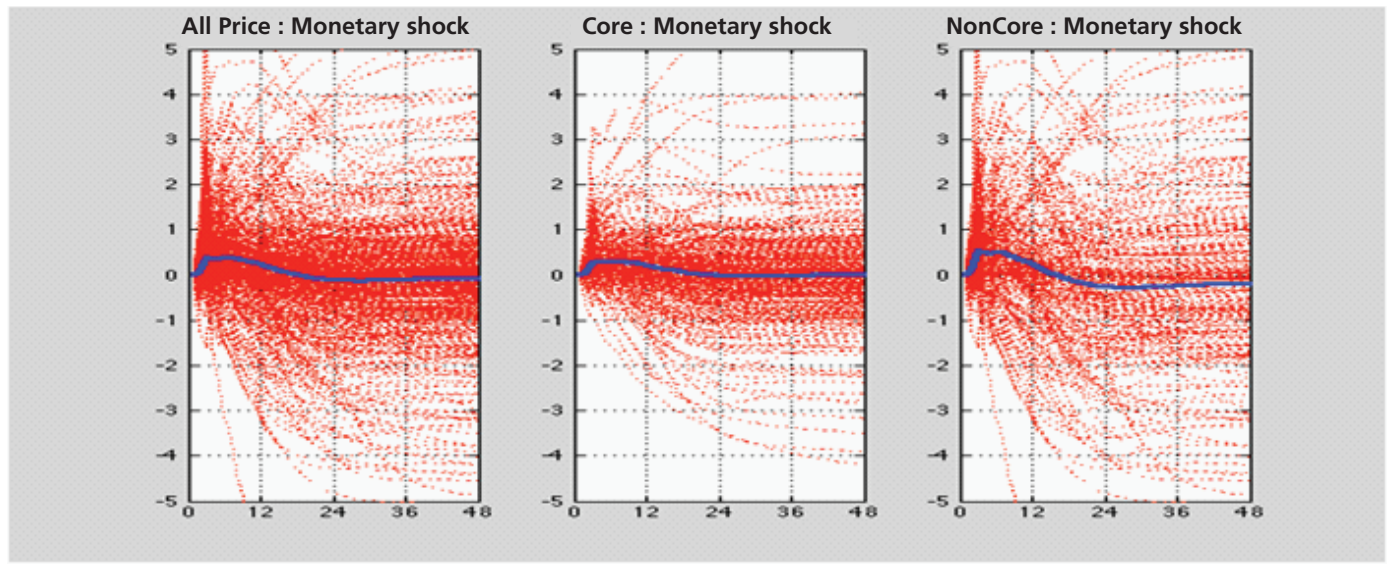

Figure 6.

Impulse Responses of Prices to Loan Rate Shocks

Up to this point, we can see different pictures given different proxies of monetary policy. The closer the proxy to the market rate, the more the puzzle tends to be reduced. The increase in deposit and loan rates has more impact on the fall in prices than the impact of a policy rate increase.Given that we examine the effect of the change in interest rate on prices using deposit rate as a proxy of market rate. 


\subsection{Impulse Responses of Prices: Pre and Post Inflation Targeting}

In the previous sections we have observed the varying impact of monetary contraction on prices. Some prices demonstrate a price puzzle, while others do not. In this section, we shall investigate what the impact of monetary contraction, represented by an increase in the deposit rate, is on prices; in particular, whether the impact is stronger or weaker after the implementation of the ITF.
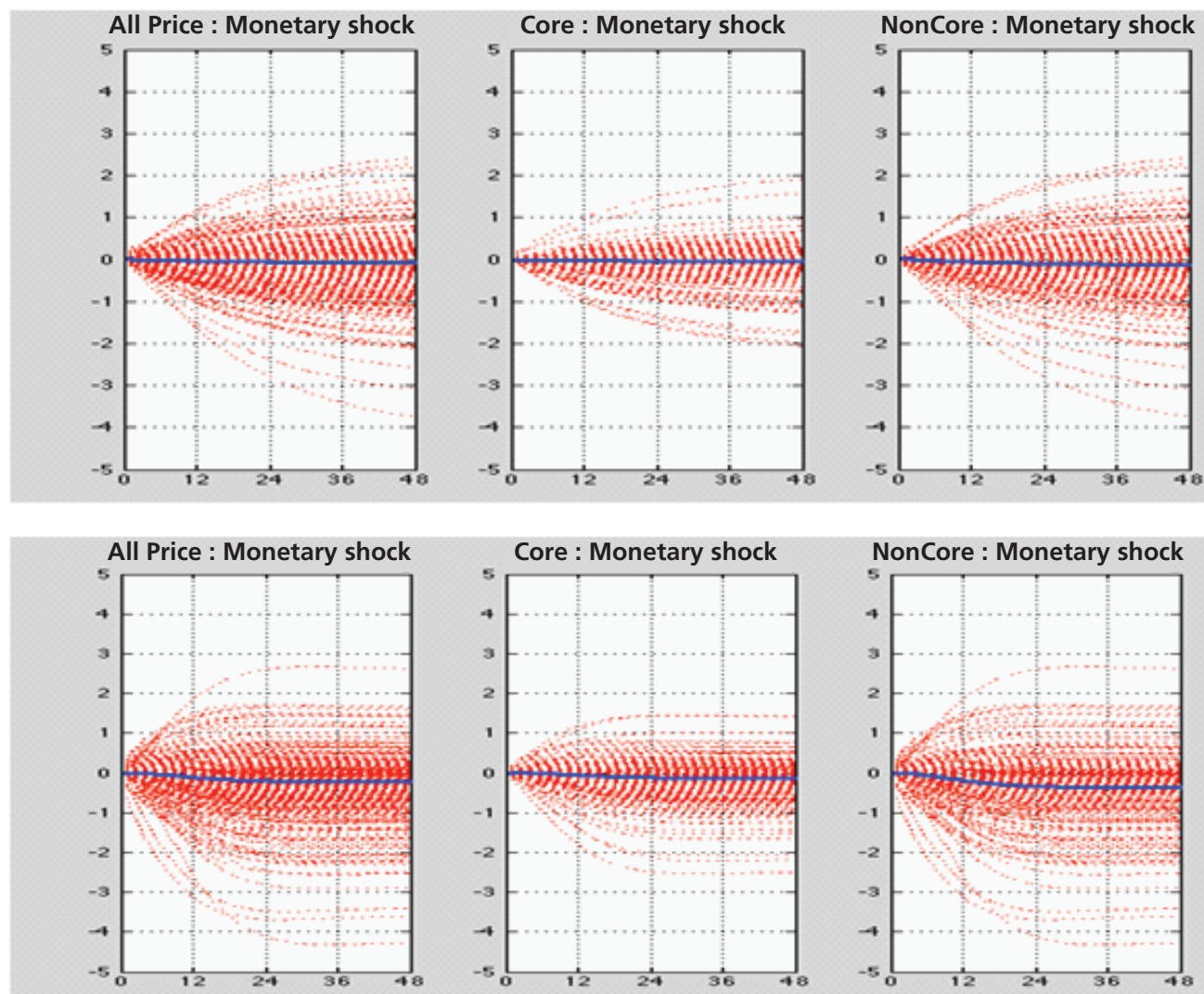

Figure 7.

Impulse Responses of Prices to Deposit Rate Shocks: Pre (upper) and Post (lower) ITF

For the period after the ITF, we obtain five factors to represent the data based on Bai and Ng's (2002) approach. We apply one lag, based on the Schwarz information criterion (SC). Even though some information criteria suggest two lags, we choose one. If using more than one lag, the impulse responses are more volatile, given the limited number of observations. For the period before July 2005, we use two factors and one lag based on the same procedure and reasoning. We find the impact of the changes in deposit rate is stronger after the implementation 
of ITF, as shown in the lower panels of figure 7. On average, prices decrease after 12 months. In contrast, before the ITF is implemented formally, the average of prices is more inert after a monetary contraction. Comparing the groups of prices, on average non-core prices decrease more than core ones.

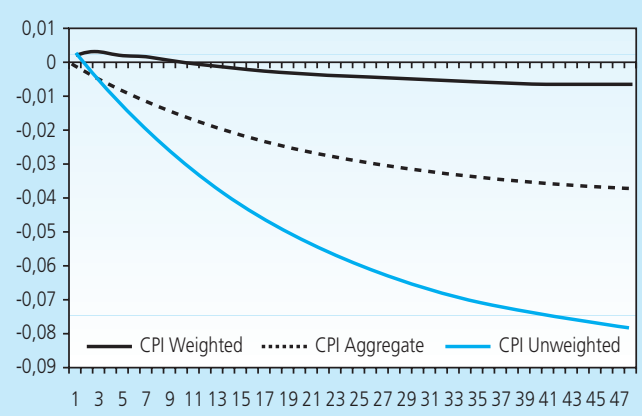

Figure 8.

Impulse Responses of CPI: Pre (left) and Post (right) ITF

If we examine the comparisons across the aggregate $\mathrm{CPI}$, the unweighted average and the weighted $\mathrm{CPI}$ as shown in the right panel of figure 8 , the price puzzle disappears in the period of ITF for all CPI definitions. Before full implementation, the weighted CPI still exhibits the puzzle. Moreover, the impact of interest rates on CPI is more apparent after the implementation of ITF. CPI decreases significantly for up to 24 months following the deposit rate increase and reaches its new long run equilibrium after that. Meanwhile, the decrease in CPI before the ITF is not as marked as in the ITF period.

A possible explanation is revealed by Castelnuovo and Surico (2010). Using a VAR model, they find a price puzzle before the Paul Volcker era (pre-1979) for the US data. They support the argument that price puzzles typically emerge in the sub sample associated with weak central bank responses to inflationary pressure. During a weak monetary policy response, inflation expectations are remarkably high. This is not captured by a VAR model and creates a price puzzle.

In our case, before the ITF, monetary policy was eclectic, in the sense that the instruments used varied, such as base money and interest rates. The mixed monetary instruments make the signal unclear. One instrument may generate monetary contraction, while another may result in expansion. In contrast, after the ITF the economic agents may have accepted the interest rate as the main instrument of monetary policy. The stance of monetary policy is clearer, the monetary transmission of the interest rate is stronger, and as a result the effects on prices are more marked during the ITF period. 
The absence of a price puzzle also suggests that the supply side effects become weaker after ITF implementation. In the more recent period, financial institutions have been more innovative and developed. This result in more alternative sources of funds, so monetary contraction has less influence through the cost channel. Even though credit will shrink after monetary contraction, firms may have more access to sources of finance other than credit. Another possible explanation is that the influence of the interest rate on exchange rates strengthens. As the interest rate increases, the exchange rate appreciates more significantly. As a result, imported material becomes much cheaper, which helps counterbalance the interest cost faced by firms. Overall, the supply side effect is weaker and the demand effect is dominant and leads to lower prices. This is also US evidence that the transmission of the cost channel was weaker after the Volcker era (Barth and Ramey, 2001).

\subsection{Impulse Responses of Disaggregated Prices and Some Macroeconomic variables to Monetary Policy Shock: Post Inflation Targeting}

As previously noticed in figure 8, there are differences between the impulse responses of aggregate and disaggregated prices in both pre- and post ITF. The different magnitude of the impulse responses between the aggregate prices and the average of unweighted disaggregated prices demonstrates the importance of weighting. Moreover, the aggregate CPI consists of all $\mathrm{CPI}$ prices, while the disaggregated prices cover 96 percent of CPI prices. In this section we shall examine the difference between these impulse responses. We shall also focus on the post ITF period, when the change in interest rate, in particular the deposit rate, had more impact on prices.

From table 5 we can see, in terms of aggregate prices, that the CPI decreases by 0.173 percent after 12 months. Subsequently, it is -0.28 percent and -0.291 percent after 24 and 48 months respectively. Meanwhile, the unweighted average prices of disaggregated CPI decreases by 0.109 percent after 12 months, while after 24 and 48 months, the impulse responses are -0.203 percent and -0.216 percent.

The aggregate for core prices still exhibits a puzzle up to the $6^{\text {th }}$ month. The aggregate for core prices falls 0.025 percent after the 12 months. After 24 and 48 months, it decreases by 0.066 percent and 0.073 percent respectively. Compared to the CPI, the responses are weaker. In both aggregated and disaggregated prices, the impulse responses of non-core prices are stronger than those for core prices.

Some other macroeconomic variables also change. The nominal exchange rate appreciates following the increase in the deposit rate. The increase of 25 basis points in the deposit rate appreciates the nominal exchange rate by as much as 0.5 percent after 18 months. Broad money also decreases following the monetary contraction, although not significantly. Unlike the CPI, which is rigid or only reacts after two months, the components of GDP react immediately after 


\begin{tabular}{|c|c|c|c|c|}
\hline \multicolumn{5}{|c|}{$\begin{array}{c}\text { Table } 5 \\
\text { Price Responses: Post ITF }\end{array}$} \\
\hline & \multicolumn{4}{|c|}{ Price Responses (in percent) } \\
\hline & 6 months & 12 months & 24 months & 48 months \\
\hline \multicolumn{5}{|c|}{ Aggregated prices } \\
\hline $\mathrm{CPI}$ & -0.072 & -0.173 & -0.280 & -0.291 \\
\hline Core & 0.002 & -0.025 & -0.066 & -0.073 \\
\hline Vol. Food & -0.102 & -0.207 & -0.301 & -0.306 \\
\hline Adm. Prices & -0.273 & -0.597 & -0.921 & -0.950 \\
\hline \multicolumn{5}{|c|}{ Harga Terdisaggregasi-CPI } \\
\hline - Average & -0.031 & -0.109 & -0.203 & -0.216 \\
\hline - Median & -0.006 & -0.039 & -0.080 & -0.086 \\
\hline - Minimum & -2.119 & -3.118 & -4.115 & -4.268 \\
\hline - Maximum & 1.066 & 1.848 & 2.605 & 2.629 \\
\hline - Standard deviation & 0.268 & 0.457 & 0.618 & 0.623 \\
\hline \multicolumn{5}{|c|}{ Harga Terdisaggregasi-Pokok } \\
\hline - Average & -0.010 & -0.056 & -0.117 & -0.126 \\
\hline - Median & -0.003 & -0.024 & -0.048 & -0.052 \\
\hline - Minimum & -0.960 & -1.810 & -2.488 & -2.498 \\
\hline - Maximum & 0.730 & 1.176 & 1.446 & 1.428 \\
\hline - Standard deviation & 0.160 & 0.283 & 0.388 & 0.392 \\
\hline \multicolumn{5}{|c|}{ Harga Terdisaggregasi-Non Pokok } \\
\hline - Average & -0.063 & -0.193 & -0.339 & -0.356 \\
\hline - Median & -0.017 & -0.086 & -0.191 & -0.197 \\
\hline - Minimum & -2.119 & -3.118 & -4.115 & -4.268 \\
\hline - Maximum & 1.066 & 1.848 & 2.605 & 2.629 \\
\hline - Standard deviation & 0.378 & 0.634 & 0.634 & 0.852 \\
\hline
\end{tabular}

the changes in monetary policy. Total consumption decreases by up to 0.4 percent from its initial level. This is also significant (within a 90 percent confidence interval) for up to 24 months. The 25 bps contraction also significantly affects investment, exports and imports. Exports fall by as much as 0.6 percent after the twelfth month from their initial level following the appreciation of the exchange rate, while total investment also decreases significantly by around 0.4 percent at the twelfth month and subsequently. Imports also fall because of the decrease in domestic demand, despite the exchange rate appreciation. However, this combination makes real GDP fall only slightly, and is not significant. In line with GDP, the production index also slightly decreases, but not significantly. 

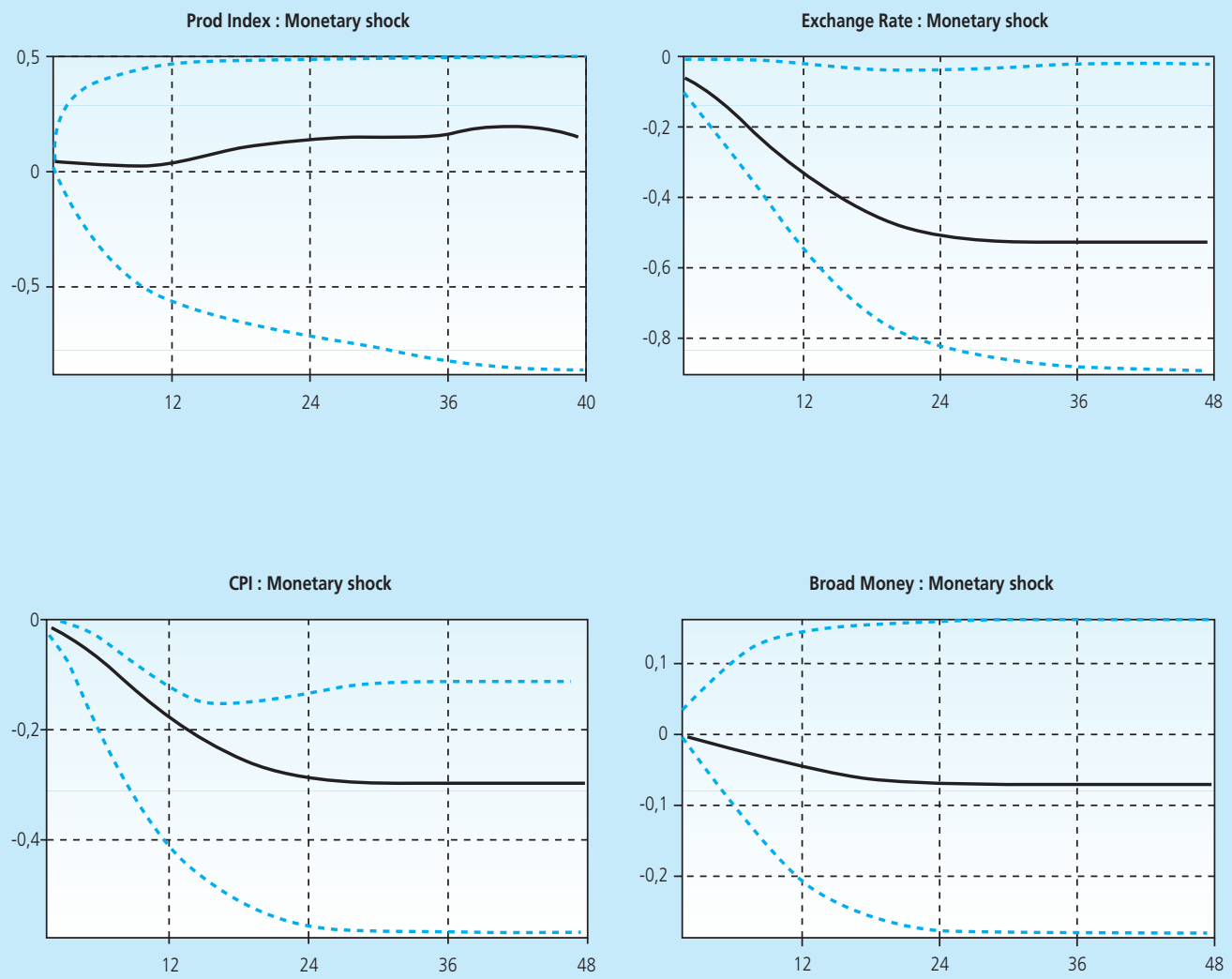

GDP : Monetary shock
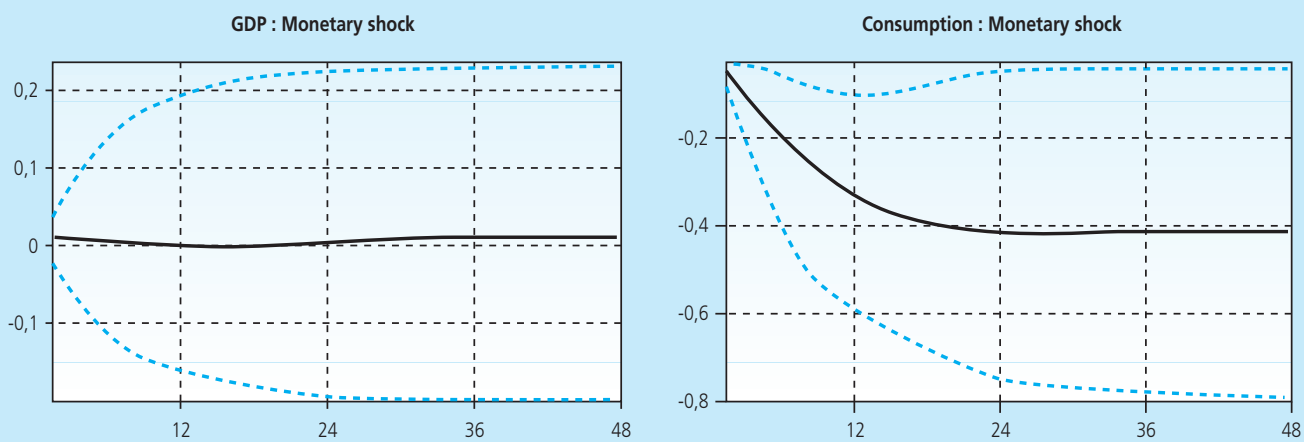

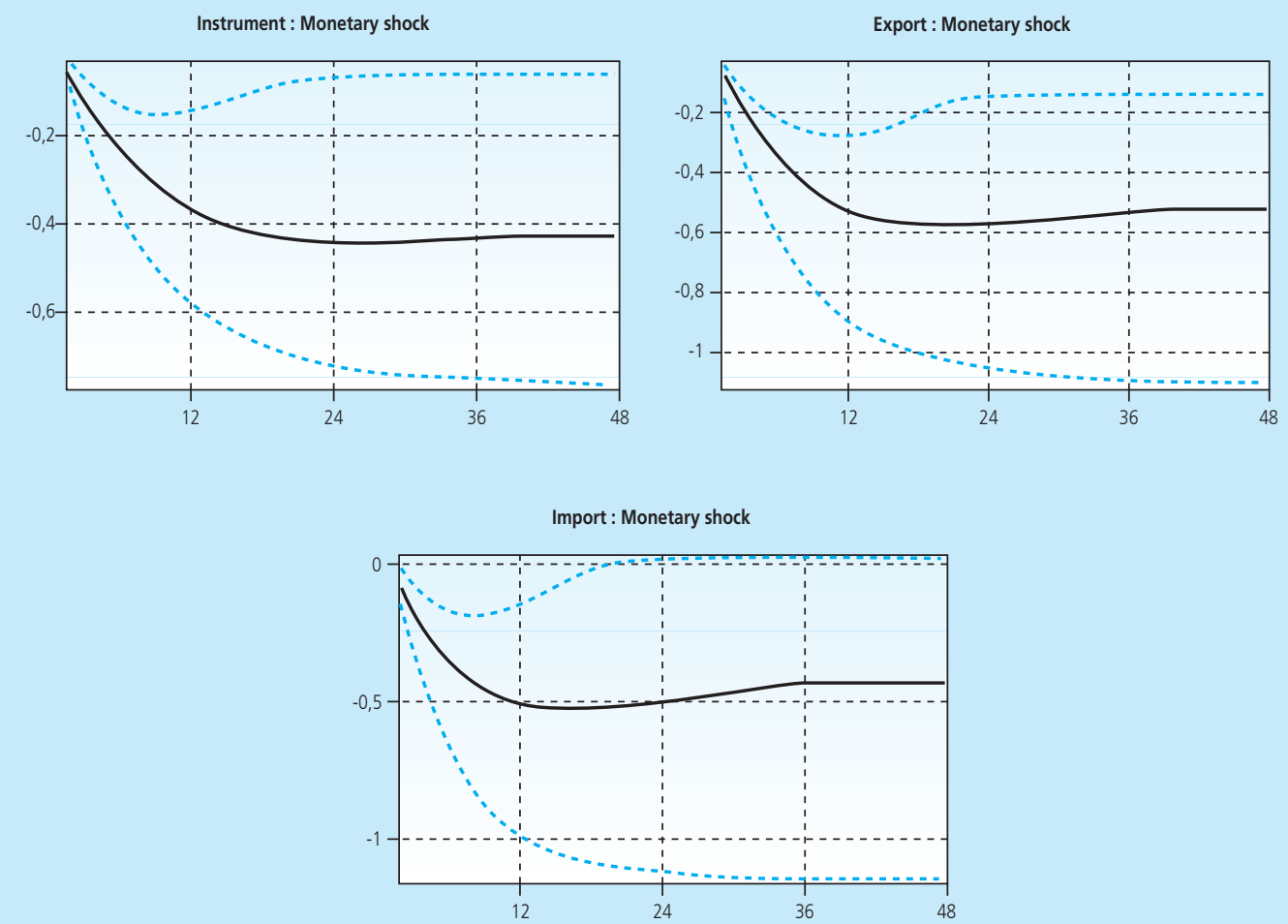

Figure 9.

Impulse Responses of Some Macroeconomic Variables

A combination of significant price decreases and relatively stable output may reflect greater price flexibility (or a steeper aggregate supply curve). From the impulse responses of prices to macroeconomic shocks and specific sector (figures 2 and 3), greater price flexibility is also confirmed as prices react immediately after the shocks, even macroeconomic ones. The persistence of inflation, both aggregated and disaggregated, is also relatively small, at less than 0.5 , compared to what is found in the US data (BGM, 2009).

\subsection{The Impulse Responses of Specific Group of Prices To Monetary Policy Shock: Post Inflation Targeting}

The previous results demonstrate the heterogeneity of price responses to monetary shocks. In order to examine this heterogeneity, we shall examine which groups of prices increase or decrease following monetary contraction. As in the previous section, we shall focus on the period after the implementation of ITF for the same reasons. 
We aggregate the impulse responses based on specific groups of core and non-core prices using the 2007 weight as the base. We divide core prices into seven groups: food and beverages (16.3), housing (19.1), clothing (6.95), health (4.37), education (4.45), entertainment (2.62) and transportation, communication and financial services (9.8). Meanwhile, we divide non-core prices into two groups: food and beverages (19.62) and others (12.87). The values in brackets are index weights.

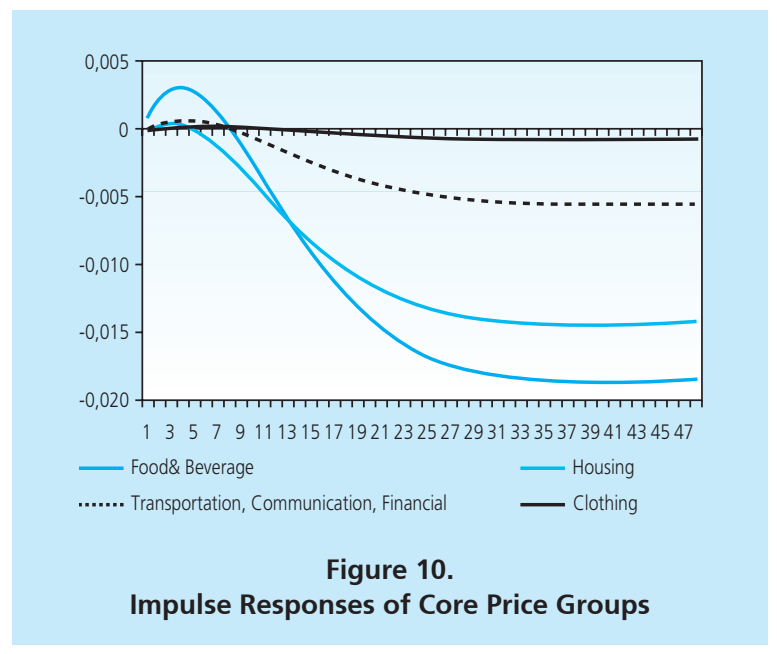

Figure 10 shows the impulse responses of four groups of prices in the core price group. On average, this set of prices falls after an increase in the deposit rate. These prices account for 52 percent of CPI. The puzzle still appears, in particular in food and beverage prices. These prices also respond more, falling by more than 0.015 percent after 24 months. On the other hand, clothing prices are steady.

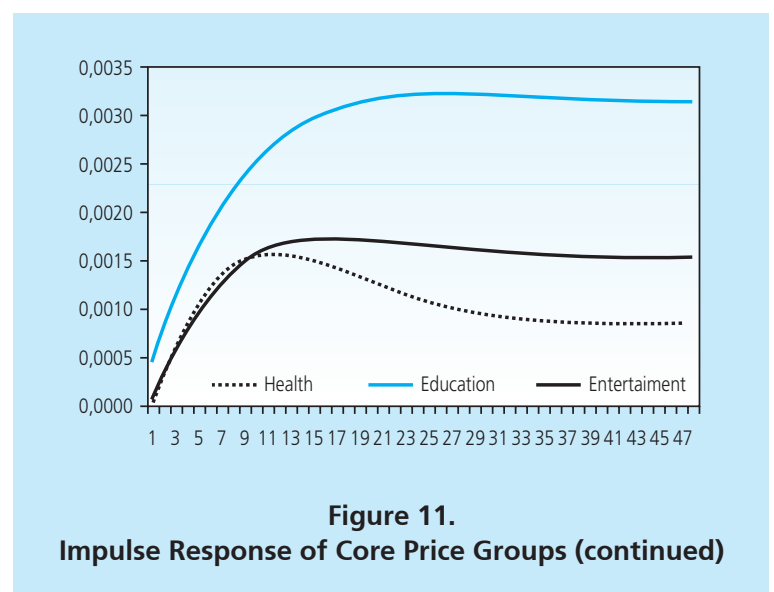


Three other groups of prices rise following monetary contraction, as shown in figure 11. Those are the health, education and entertainment groups of prices, which account for 11.4 percent of $\mathrm{CPI}$. The impulse responses are smaller than for the former group; this hints at the dominance of the cost channel in this case. If we observe the items in these groups, the producers are most likely to face enhanced credit-financing costs. These items include costs for hospital care, medicine, school and course tuition fees, and entertainment products such as music equipment and cinema. One might think that most of the firms involved in price setting in these groups are large ones, with more access to bank loans and hence more dependent on bank financing. These firms optimise the present value of their future prices in consideration of the interest rate. As the market interest rate increases, so does the interest cost. As a result, these firms set their prices higher.

Another explanation is that there may be many small firms which supply parts to those larger ones. These small firms are more sensitive to fluctuations in the loan rate. As a result, these producers cover the increase in interest costs by increasing their prices, except when service for their client is major commitment. On this case the service for client becomes a fixed cost for the firm, and they will not raise their prices even when the fixed costs have risen.

Another possible explanation is the price setting in these groups (Rotemberg, 1982). For example, the firms in these three sectors, which are non-traded, respond to the shocks by increasing their prices gradually given the price adjustment is convex. Suppose there is an exchange rate depreciation that makes policy maker reacts by increasing policy rate. As the firms have already embarked on a gradual sequence of price increase, it takes more time to see the effect of policy rate increase.

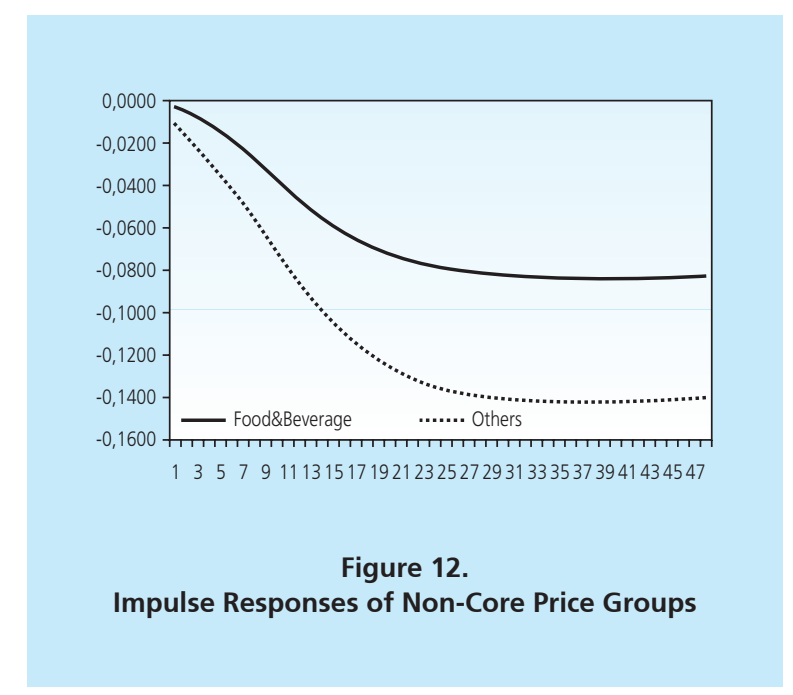


As previously mentioned, the impulse responses of non-core prices are stronger than core prices. If we observe figure 12, both groups of non-core prices exhibit falls and there is no price puzzle. The magnitudes are also bigger. Food and beverage prices, which account for 19.62 percent of the CPI, fall by up to 0.08 percent in the non-core prices. This is higher relative to the core ones, which fall less than 0.02 percent. Others prices fall even more by -0.14 percent starting from $24^{\text {th }}$ month.

Assuming that the deposit rate strongly influences aggregate demand in the economy, the above figures demonstrate that prices in the housing sectors, food sectors and all noncore prices are sensitive to demand factors. On the other hand, prices in health, education and entertainment are more sensitive to cost factors. As interest rates increase, the costs of production in these sectors also increase and hence prices rise. The larger group of prices, the larger it falls following interest rate increases. As these prices have more weight, the CPI in aggregate also decreases. The above figure shows the CPI, either the non-weighted, weighted, or the aggregate one decline with similar path.

\section{CONCLUSION}

The effect of monetary policy on inflation, which involves changes in policy rate, is not immediate and demonstrates distributed lags. A major challenge is to identify the response speed of inflation due to shock from policy rate as well as from other macroeconomic variables. It is therefore crucial to investigate the lag structure for inflation in following policy rate changes. Furthermore, many econometricians have discovered that the movement of inflation is perverse after the policy rate changes. They usually use a broad measurement index such as CPI to examine the dynamic of inflation. Understanding the forces behind the lag and the initial perverse effect is greatly assisted by scrutinizing the dynamics of individual components of this index. By that, we can have a better understanding how prices respond differently across sectors to monetary policy changes.

This paper scrutinizes the inflation dynamics in Indonesia using disaggregated CPI data. We use FAVAR, as in BGM. This technique allows us to analyze both aggregate and disaggregated prices with the same framework simultaneously. By employing disaggregated data, we deal with the combination of a large number of data with a limited number of observations. FAVAR provides a solution for this condition.

The first finding of this paper is that price behavior in Indonesia exhibits heterogeneity. It is evident not only in terms of the magnitude, but also in the direction and the speed of adjustment to their new equilibrium. This heterogeneity becomes clearer when we examine the behavior of groups of prices in the period after full implementation of ITF. We find that monetary policy shocks have varying impacts on these groups of prices. More sectors respond by lowering their prices following a deposit rate increase, which reflects the dominance of demand factors. 
These sectors are food and beverages; housing; transportation, communication and financial services; clothing, and others. They also respond to different degrees. Meanwhile, prices in the entertainment, health and education sectors respond by rising. This may be because the supply side effect is dominant in these groups of prices. Another possible explanation is price adjustment costs in these sectors, which are non-traded, are convex (as in Rotemberg, 1982). The firms may already have embarked on a gradual sequence of price increases, from which deflation will take more time following a policy rate increase.

The second finding of this paper is that the source of the shock matters. Our estimation results show that the volatility of inflation mainly comes from the volatility of sector specific shocks rather than macroeconomic ones in both aggregate and disaggregated inflation, and both in core as well as non-core inflation. The heterogeneity is therefore not only in terms of the magnitude of the responses and the speed of adjustment, but also which factors are more dominant within group of prices. This result is different from Boivin, Giannoni and Mihov (2009) who showed that the source of the volatility of aggregate inflation in the US was different from disaggregated inflation. For them, the volatility apparent in disaggregated inflation, as shown in Bils and Klenow (2004), is mostly related to sector specific shocks, and is not attributed to macroeconomic shocks, particularly a monetary one. On the contrary, the volatility of aggregate inflation is mostly related to macroeconomic shocks.

The third finding is that disaggregated prices are more flexible in response to sector specific shocks, since they reach their new equilibrium more rapidly. The magnitudes of impulse responses are also larger. Disaggregated prices are more sluggish in response to macroeconomic shocks; although they also react instantaneously but take longer time to reach a new equilibrium. The speed of adjustment due to macroeconomic shocks is slower than that of sector specific shocks. This conclusion is in accordance with that of BGM who used US data.

The fourth finding of this paper is that the deposit and loan rates have more impact on prices relative to policy rate. A positive shock on the deposit or loan rate can lower prices, albeit with lags, given the puzzle in the initial period. Using recursive identification, we firstly impose a shock on the policy rate and find a persistent price puzzle, where prices tend to increase in response to monetary contraction. We replace the policy rate with three-month deposit rate and loan rate, but the puzzle still exist even though no longer persistent.

Related to ITF implementation, the fifth finding of this paper is that the implementation of ITF is successful in leading prices through movements in the deposit rate. We separate the sample into two periods based on the full implementation of ITF and find that the puzzle weakens once ITF is adopted, even disappearing if we impose one lag after the ITF.

The sixth finding is that monetary contraction squeezes the components of GDP. Given the stronger effect of the deposit rate on prices under ITF, we also examine the impulse responses of various macroeconomic variables during this period. Exports decrease as the exchange rate 
appreciates and consumption and investment also fall. Imports also decrease significantly as domestic demand falls. Overall, the decrease in aggregate prices is stronger than in output, which may suggest a steep aggregate supply curve or more flexible prices.

The policy implication, especially related to the second the third finding, is that the pursuit of price stability calls for careful inspection of specific aspects of prices in addition to the movement of macroeconomic variables. For instance, policy makers should watch and predict the movements of some indicators that are closely associated with some prices that have high weights on the CPI. This provides a way of anticipating the movement of those prices in the future.

Related to future research, this paper has found a negative correlation between the persistence and the volatility of inflation, in both core and non-core inflation. This matches the prediction of the Calvo model and might suggest that this model is suitable for capturing the inflation volatility and persistence in Indonesia. As this negative correlation is stronger in the sector specific component, the Calvo model might be more suitable on explaining the fluctuations in inflation volatility and persistence in facing sector specific shocks. Confirming this possibility is important.

Furthermore, at least two interesting questions follows; first, which class of model can best mimic price behavior in Indonesia: a time dependent or a state dependent model? Even though there is an indication that time dependent models such as the Calvo one are not inconsistent with price behavior in Indonesia, it would be worth confirming this. Second, related to the price puzzle, it would be interesting to explore whether demand or supply factors are more influential in price behavior. 


\section{REFERENCES}

Bai, J. and Ng, S., 2002, "Determining the Number of Factors in Approximate Factor Models." Econometrica, 70(1), pp. 191-221.

Balke, N.S. and Emery, K.M., 1994, "Understanding the Price Puzzle." Federal Reserve Bank of Dallas Economic Review, Fourth Quarter.

Barth III, M.J. and Ramey, V.A., 2002, "The Cost Channel of Monetary Transmission," Nber Macroeconomics Annual 2001, Volume 16. MIT Press, 199-256.

Bernanke, B.S.; Boivin, J. and Eliasz, P., 2005, "Measuring the Effects of Monetary Policy: A Factor-Augmented Vector Autoregressive (Favar) Approach." The Quarterly Journal of Economics, 120(1), pp. 387-422.

Bils, Mark and Klenow, Peter J., 2004, "Some Evidence on the Importance of Sticky Prices." Journal of Political Economy, 112(5), pp. 947-85.

Boivin, Jean; Giannoni, Marc P. and Mihov, Ilian., 2009, "Sticky Prices and Monetary Policy: Evidence from Disaggregated Us Data." American Economic Review, 99(1), pp. 350-84.

Bunn, P. and Ellis, C., 2012, "Examining the Behaviour of Individual Uk Consumer Prices." The Economic Journal, 122(558), pp. F35-F55.

Calvo, Guillermo A., 1983, "Staggered Prices in a Utility-Maximizing Framework." Journal of Monetary Economics, 12(3), pp. 383-98.

Castelnuovo, E. and Surico, P., 2010, "Monetary Policy, Inflation Expectations and the Price Puzzle." The Economic Journal, 120(549), pp. 1262-83.

Christiano, L.J.; Eichenbaum, M. and Evans, C., 1994, "The Effects of Monetary Policy Shocks: Some Evidence from the Flow of Funds." NBER Working Paper.

1996, "The Effects of Monetary Policy Shocks: Evidence from the Flow of Funds." The Review of Economics and Statistics, 78(1), pp. 16-34.

Christiano, L.J.; Eichenbaum, M. and Evans, C.L., 1999, "Monetary Policy Shocks: What Have We Learned and to What End?" Handbook of macroeconomics, 1, pp. 65-148.

Golosov, Mikhail and Lucas, Robert E., Jr., 2007, "Menu Costs and Phillips Curves." Journal of Political Economy, 115(2), pp. 171-99. 
Rotemberg, Julio J., 1982, "Sticky Prices in the United States." Journal of Political Economy, 90(6), pp. 1187-211.

Sims, C.A., 1992, "Interpreting the Macroeconomic Time Series Facts: The Effects of Monetary Policy." European Economic Review, 1992, 36(5), pp. 975-1000.

Stock, J.H. and Watson, M.W., 2010, "Dynamic Factor Models." Oxford Handbook of Economic Forecasting, Oxford University Press, Oxford, UK.

Millard, S., \& O'Grady, T., 2012, "What do sticky and flexible prices tell us?" Bank of England Working Paper. 